\title{
Comparing two models of outpatient specialised palliative care
}

\author{
Elizabeth Rosted ${ }^{1,2^{*}}$, Birgit Aabom ${ }^{1}$, Bibi Hølge-Hazelton ${ }^{2,3}$ and Mette Raunkiær ${ }^{4}$
}

\begin{abstract}
Background: Ideally, patients with life-threatening illness who are suffering from multiple symptoms and reduced quality of life should receive palliative care that addresses their specific needs. The many well-defined clinical pathways may not always leave room for a person-centred and individual approach with respect to symptom control, psychosocial and spiritual support, and practical issues. In deciding how to organize outpatient specialist palliative care (SPC), it is relevant to include the perspectives of both patients and families. Thus, the aim of this study was to compare two models for outpatient SPC: first contact between patient, next-of-kin and doctor/nurse in the form of a home visit; and first visit in the hospital setting.

Method: The study was a comparative mixed methods study with follow-up at one and 3 months. It started with a quantitative strand in the form of a 38-item questionnaire. Data were analysed using linear mixed effects models, with maximum likelihood estimation for each outcome variable. The repeated measurements on patient level were modelled by including random intercepts of patients in the mixed model.

Results: In total, 190 participants were enrolled, of whom 102 answered the first questionnaire. No differences were found between the two SPC interventions when development in satisfaction with care, communication or overall quality of life were compared. At baseline, a significantly higher score for satisfaction was found, in favour of first visit taking place in the hospital setting (65.91 vs. 55.83; $p=0.03$ ) measured by FAMCAREP16, and more patients were satisfied with availability of nurses and their abilities to listen and communicate than of doctors.
\end{abstract}

Conclusion: Specialist palliative care is in request for many patients in the late phase of their disease. We found no significant differences in satisfaction with care, communication with health professionals or in overall quality of life between the two models. This may imply that access to SPC is more important than the model that is applied, and that a person-centred approach together with time available may matter more than the context. These two factors should be considered when implementing SPC.

\footnotetext{
* Correspondence: eros@regionsjaelland.dk

'Department of Oncology and Palliative Care, Zealand University Hospital, Sygehusvej 10, 4000 Roskilde, Denmark

${ }^{2}$ Department of Regional Health Research, University of Southern Denmark, J.

B. Winsløws Vej 19,5000 Odense C, Denmark

Full list of author information is available at the end of the article
}

(c) The Author(s). 2021 Open Access This article is licensed under a Creative Commons Attribution 4.0 International License, which permits use, sharing, adaptation, distribution and reproduction in any medium or format, as long as you give appropriate credit to the original author(s) and the source, provide a link to the Creative Commons licence, and indicate if changes were made. The images or other third party material in this article are included in the article's Creative Commons licence, unless indicated otherwise in a credit line to the material. If material is not included in the article's Creative Commons licence and your intended use is not permitted by statutory regulation or exceeds the permitted use, you will need to obtain permission directly from the copyright holder. To view a copy of this licence, visit http://creativecommons.org/licenses/by/4.0/ The Creative Commons Public Domain Dedication waiver (http://creativecommons.org/publicdomain/zero/1.0/) applies to the data made available in this article, unless otherwise stated in a credit line to the data. 


\section{Background}

Patients with life-threatening illness often suffer from reduced quality of life (QOL) and multiple symptoms, such as pain, fatigue, and dyspnoea, related to their illness and/or its treatment [1,2]. Ideally, these patients should receive palliative care that addresses their specific needs. The many well-defined clinical pathways, i.e. the overarching guidelines for medical treatment, care and follow-up, in general ensure that this care is made available, but they may not always leave room for a personcentred and individual approach in respect to symptom control, psychosocial and spiritual support, along with practical issues $[3,4]$.

In 2019, 10,160 patients in Denmark suffering from cancer and 1133 with other diagnoses were referred to specialist palliative care (SPC). The median survival from first contact with the team was only 38 days for the cancer patients and 37 days for patients suffering from other diagnoses [5]. Referral to SPC thus occurs late in life and, for some patients, this leaves health professionals with little time to arrange and evaluate care, which is why it is important to learn from other patients' and carers' experiences when developing practice. The Danish Health Authority defines palliative care in line with the World Health Organization's definition [6], as described in Table 1.

In Denmark, the hospitals are responsible for SPC. The care may be organised as either inpatient hospitalisation or at outpatient clinics. Inpatient care in this context refers to care provided to hospitalised patients by an SPC consultation service. Outpatient refers to care provided to non-hospitalised patients who either visit a clinic at the hospital or receive home visits by the SPC consultant team from the hospital SPC consultation service.

Two recently published meta-analyses, including both inpatient and outpatient SPC, showed that interventions were associated with improvements in patient QOL [7, 8], while only one found a positive result for symptom management [8]. Of the 43 included studies in the latter

Table 1 Understanding of Generalist and Specialist Palliative Care

In Denmark, the World Health Organization' definition of palliative care is used by the Danish Health Authority. Its is an approach that

"improves the quality of life of patients and their ffamilies facing the problems associated with life-threatening illness...". It must "be available in all care settings for patients with moderate to high complexity of need, and is provided by health and social professionals who specialise in palliative care and work within a multi-professional specialist palliative care team" [6].

Specialist palliative care differs from generalist palliative care that is provided for patients and their families with low to moderate complexity of palliative care need. Generalist palliative care is defined as "care provided to those affected by life-threatening as an integral part of standard clinical practice provided by any healthcare professional who is not part of a specialist palliative care team" [6]. meta-analysis, satisfaction with care was assessed in 11 trials and, of those, seven reported a significant improvement in satisfaction among SPC recipients [8]. It is not clear whether the type of intervention - inpatient or outpatient - was of importance.

From the patient perspective, personalised care provided by inter-professional teams and communication are key elements of the experience of quality of care and satisfaction [9-11]. Depending on their illness, however, patients may have divergent palliative care needs, which the SPC team should be in a position to address. Personalised palliative care should be tailored to provide the right level of intervention for the right patient in the right setting at the right time [11].

In an interview study, Wentlandt et al. (2016) identified six themes of importance in relation to quality of care and satisfaction in palliative care units. Both patients and families emphasized the importance of an interdisciplinary team for the management of SPC, i.e. doctor, nurse, physiotherapist, nutritional therapist, social worker, psychologist and priest; that the care is attentive and personalised; and that it is family-centred. In addition, the authors found that SPC should be allocated appropriate resources and adequate staffing to provide consistent care, and that the setting should be noninstitutionalized, thereby allowing for both privacy and socialization [10]. Communication was the most prevalent theme, which encompassed the following: the SPC team should address expectations and explain care goals, keep patients and families informed about the patient's condition, listen actively to validate patients' concerns and individual needs, and provide a safe space for conversations about death and dying [10]. These results are consistent with the qualitative results of a systematic review of patients', families', and staff's satisfaction with end-of-life care [12]. In regard to the intervention studies included in the review, Dy et al. (2008) found that palliative care and hospice teams improve patient and family satisfaction. However, it was also found that many studies does not include satisfaction as an outcome, and that more focus on satisfaction-based elements might improve the effectiveness of end-of-life care interventions and their evaluation [12].

While many researchers have studied in-hospital SPC, much fewer have investigated outpatient SPC in connection with home visits $[13,14]$. As a result of this, many published studies does not include standardized outpatient SPC- models. For this reason, it can be problematic to compare interventions, organization or clinical results [13]. In a review study, Hui et al. (2018) found that studies involving interdisciplinary SPC teams were more likely to have a positive outcome than those involving solely nurse-led palliative care, though no single study directly compared interdisciplinary teams with 
single-practitioner-led models [11]. A review from 2013 found only four well-designed RCTs, but a growing body of non-randomized studies that indicated that outpatient SPC may: improve patient satisfaction, symptom control and QOL; reduce health care utilization; and lengthen survival in a lung cancer population [13]. In addition, only four studies concerning outpatient SPC were found by Zimmermann et al. (2008). Three of those showed significantly improved satisfaction when receiving SPC [15].

This seems to show that both inpatient and outpatient SPC improves patient satisfaction, but it is not clear how the outpatient SPC were organized, as the studies do not describe a standardized outpatient SPC model. However, it is clear that core elements of quality of care and satisfaction are personalised care by inter-professional teams and the teams' ability to communicate open-minded [9, $10,16]$. This is an individual approach to symptom control, psychosocial and spiritual support, together with practical issues.

In Denmark, most patients are very satisfied with the SPC they receive, however the factors of age, marital status and place of care were found to have some impact, in a nationwide survey from 2012 [17]. In other studies that examined the effect on early SPC no difference were found between intervention and standard care $[18,19]$.

Although several issues may be common to patients and families, studies show that factors important to quality at the end of life differ by role and by individual $[17,20,21]$. Models may vary in relation to different national health and welfare systems, geography, culture and traditions, and the literature does not clearly prescribe a model for outpatient SPC [22]. Thus, when deciding how to organize outpatient SPC in the future, it is relevant to study outpatient SPC and include both patients' and families' perspectives.

Thus, the overall aim of this study was to compare two different models for outpatient SPC, i.e. first contact between patient, next-of-kin and doctor/nurse in the form of a home visit, and the first visit taking place in the hospital setting. This was with a view to gaining new knowledge about satisfaction, symptom control and QOL in relation to outpatient SPC and to include this knowledge in future service planning and organization.

\section{Method}

\section{Design}

The study was a comparative mixed methods study with an explanatory sequential design. It started with a quantitative strand, in the form of a questionnaire, through which general trends and relationships were examined. Results from the quantitative analysis then determined which results needed further exploration in the form of in-depth personal perspectives and what questions to ask participants in the qualitative interview phase [23]. This paper presents results from the quantitative strand - a 38-item questionnaire.

\section{Participants and setting}

The setting was the outpatient SPC units at the Department of Oncology and Palliative Care at Zealand University Hospital, Denmark. In January 2016, the oncological and palliative care departments at five local hospitals in the area of Region Zealand had been merged into one overarching department. The newly re-organized outpatient SPC unit was to have two sections - one located at two hospitals, Roskilde and Koege $(\mathrm{R} / \mathrm{K})$ and the other section at three hospitals, Naestved, Slagelse and Nykoebing F $(\mathrm{N} / \mathrm{S} / \mathrm{N})$. Outpatient SPC was organized differently at the two sections, which offered the opportunity to compare the two models. In 2017, 371 patients were treated at the outpatient sections $\mathrm{R} / \mathrm{K}$ and 667 at $\mathrm{N} / \mathrm{S} / \mathrm{N}$ [24]. The median length of time from patients' admission to death was about 3 months. Two of the hospitals associated with the outpatient SPC teams could offer admission to an inpatient SPC unit, if it were required for a patient's care. Other SPC options in the region were three independent hospices, with a total capacity of 682 admitted patients in 2017 [24].

All adult patients registered to one of the two outpatient SPC sections during 2017 received written information about the study at their first consultation. Those who consented received a telephone call from the researcher within the following week informing them about the study and asking them to complete the questionnaire. Those who consented were included and returned a written consent. Patients were excluded if they did not understand or speak Danish, or if they were considered to be unable to participate due to physical, mental or social reasons, as assessed by the SPC nurses at the first consultation, based on their clinical knowledge.

\section{The specialised palliative care interventions}

The overall purpose of the SPC teams work at Zealand University Hospital is defined by the Danish Health Authority in line with the World Health Organization's definition of SPC [6, 25].

The primary differences between how the two teams in our study worked were how the first contact was made and the procedure for follow-up. At $\mathrm{R} / \mathrm{K}$, the first consultation took place in the hospital setting and follow-up consisted of SPC team consultations every 3 weeks and additional follow-up telephone calls by the SPC nurse. At N/S/N, the first visit by the SPC team was a home visit, and follow-up was conducted primarily by the patient's general practitioner (GP) and the community home care nurse, who was a non-specialist 
palliative care nurse. Table 2 shows the two different interventions.

\section{Outpatient SPC team at $R / K$}

The SPC team at $\mathrm{R} / \mathrm{K}$ is interdisciplinary and consists of palliative care physicians and nurses, a physiotherapist, a dietician, a social worker, a psychologist and a priest. The team holds weekly interdisciplinary meetings. The core intervention was consultation and follow-up in the palliative care outpatient clinic at the hospital by a palliative care physician and nurse, consisting of comprehensive, multidisciplinary assessment of symptoms, psychological distress, social support and home services. The first consultation lasted about 1 hour. Follow-up consultations were scheduled every 3 weeks or as required, either in the form of a consultation with the palliative care physician and nurse or with the nurse alone.
The follow-up consultation was scheduled to last half an hour. In addition, telephone follow-up by an SPC nurse was offered on a regular basis. If the patient was too ill to consult the team at the hospital, a home visit could be arranged. A telephone hotline for urgent issues was available for 2 hours daily. If patients had SPC needs, they were offered follow-up until the end of life. Ancillary interventions, depending on the status of the patient, included arrangement of community home care nursing, by a non-specialist palliative care nurse, referral to one of three hospices, or admission to the inpatient SPC unit at Zealand University Hospital for urgent symptom control or terminal care.

\section{Outpatient SPC team at N/S/N}

The SPC team at N/S/N was also interdisciplinary, but had a different staff make-up: palliative care physicians

Table 2 Specialised Palliative Care interventions at the two study locations

\begin{tabular}{|c|c|c|}
\hline Outpatient clinics & $\mathrm{R} / \mathrm{K} \mathrm{SPC}$ team & N/S/N SPC team \\
\hline Capacity & 180 & 280 \\
\hline $\begin{array}{l}\text { The team receive } \\
\text { referrals from: }\end{array}$ & $\begin{array}{l}\text { Hospital physician } \\
\text { Private practitioners } \\
\text { Other professionals at the hospital } \\
\text { Professionals at hospices } \\
\text { Family doctor } \\
\text { Home care nurse } \\
\text { Professionals at nursing homes and community day centre } \\
\text { Patients themselves } \\
\text { Patients' family members }\end{array}$ & $\begin{array}{l}\text { Hospital physician } \\
\text { Private practitioners } \\
\text { Professionals at hospices } \\
\text { Family doctor }\end{array}$ \\
\hline $\begin{array}{l}\text { Pre-admission } \\
\text { assessment for the } \\
\text { SPC teams }\end{array}$ & $\begin{array}{l}\text { Pre-admission assessment is carried out daily and patients in } \\
\text { need of specialised palliative care, regardless of their diagnoses } \\
\text { or age, are accepted }\end{array}$ & $\begin{array}{l}\text { Preadmission assessment is carried out daily and patients in } \\
\text { need of specialised palliative care, regardless of their } \\
\text { diagnoses or age, are accepted }\end{array}$ \\
\hline SPC team staff & $\begin{array}{l}\text { Palliative care physicians } \\
\text { Palliative care nurses } \\
\text { Physiotherapist } \\
\text { Social worker } \\
\text { Priest } \\
\text { Dietician } \\
\text { Psychologist }\end{array}$ & $\begin{array}{l}\text { Palliative care physicians } \\
\text { Palliative care nurses } \\
\text { Physiotherapist } \\
\text { Social worker } \\
\text { Priest }\end{array}$ \\
\hline $\begin{array}{l}\text { Location of } \\
\text { outpatient } \\
\text { consultations }\end{array}$ & $\begin{array}{l}\text { Primarily at the outpatient clinic located at the hospital } \\
\text { Home visits }\end{array}$ & Always home visits \\
\hline $\begin{array}{l}\text { Duration of } \\
\text { association with } \\
\text { the SPC team }\end{array}$ & From pre-admission assessment to end of life & $\begin{array}{l}\text { From pre-admission assessment to well established palliative } \\
\text { care, as agreed by patient, family and health professionals }\end{array}$ \\
\hline $\begin{array}{l}\text { Hotline service for } \\
\text { patients }\end{array}$ & $\begin{array}{l}\text { Two hours during daytime on weekdays, provided by palliative } \\
\text { care nurses }\end{array}$ & $\begin{array}{l}\text { During daytime on weekdays, provided by palliative care } \\
\text { nurses }\end{array}$ \\
\hline $\begin{array}{l}\text { Hotline service for } \\
\text { professionals }\end{array}$ & $\begin{array}{l}\text { 24-hotline service, provided by palliative care physicians and } \\
\text { nurses. Offered to professionals from hospitals, nursing homes, } \\
\text { family doctors, primary healthcare nurses and other who may } \\
\text { call. }\end{array}$ & $\begin{array}{l}\text { During the daytime on weekdays, provided by palliative care } \\
\text { physicians and nurses. Offered to professionals from hospitals } \\
\text { and nursing homes }\end{array}$ \\
\hline $\begin{array}{l}\text { Routine offer of } \\
\text { care to family }\end{array}$ & Yes & Yes \\
\hline $\begin{array}{l}\text { Routine offer of } \\
\text { care to bereaved } \\
\text { family }\end{array}$ & Yes & No \\
\hline Approach to care & $\begin{array}{l}\text { Multidisciplinary, addressing physical, psychological, social and } \\
\text { spiritual needs }\end{array}$ & $\begin{array}{l}\text { Multidisciplinary, addressing physical, psychological, social and } \\
\text { spiritual needs }\end{array}$ \\
\hline
\end{tabular}


and nurses, a physiotherapist, a social worker and a priest. Weekly interdisciplinary meetings were held. The core intervention was a home visit consultation by a palliative care physician and nurse, consisting of a comprehensive, multidisciplinary assessment of symptoms, psychological distress, social support and home services, with follow-up primarily conducted by a palliative care nurse. The first home visit lasted between one and 2 hours. Most patients received one follow-up home consultation, and one or two follow-up phone calls by the SPC nurse, as needed, and then the patient's GP and home care nurses assumed responsibility for the palliative care. A telephone hotline for urgent issues was available during the daytime. Ancillary interventions, depending on the status of the patient, included: arrangement of community home care nursing service by a non-specialist palliative care nurse, referral to one of the three hospices or admission to the inpatient oncological unit at Zealand University Hospital, or to a general medical ward, for urgent symptom control or terminal care. The SPC team could refer patients to the local hospices, who would then do a pre-admission assessment, before the patients were admitted. The SPC teams and the hospices worked in close partnership, as some SPC doctors also served the hospice and - as is the case in other countries - the hospice was the provider of SPC in the community. Admission to hospices is free of charge in Denmark.

\section{Data collection}

Participants were included from January until December 2017. Questionnaires were sent at inclusion after the first SPC team consultation and after one and 3 months, either by ordinary post in a paper version with a franked reply envelope or by email, as a link to the online survey, in accordance with patients' choices. The online survey was developed in SurveyXact ("SurveyXact by Ramboll" 2018), a secure data management application that has certified access and encrypted communication. Reminders were sent to those who had not returned or started the questionnaire within 14 days. Two further reminders were sent, respectively, two and 4 weeks after the first reminder.

Primary outcome was participants' satisfaction with care and communication. To measure satisfaction with care, we used the family satisfaction scale (FAMCAREP16). It is a 16-question questionnaire measuring satisfaction in relation to information-giving, availability of care, psychological care and physical care. The score ranges from 16 to 80; the higher the scores, the greater satisfaction [26, 27]. The Cancer Patient's World Questionnaire (CPWQ-com) measured satisfaction with communication [28]. This brief questionnaire consists of seven questions; the score was transferred to a sum rating from zero to 100, and higher scores indicated greater satisfaction [28].

Secondary outcomes were participants' symptom control, physical and emotional function and quality of life. Those were measured by European Organization for Research and Treatment of Cancer Quality of Life Questionnaire Core 15 - Palliative Care (EORTC QLQC15-PAL) [29], which is a 15-item abbreviation of the EORTC QLQ-C30, developed by European Organization for Research and Treatment of Cancer [30]. It comprises a global health-status scale, two multi-item functional scales (physical functioning and emotional functioning), two multi-item symptom scales (fatigue and pain), and five single-item symptom scales (nausea and vomiting, dyspnoea, insomnia, appetite loss and constipation). Responses are measured in 4-level to 7-level Likert scales; 7-level for global health status and 4-level for the remaining scales, which were linearly transformed into a score of zero to 100; higher scores represent best global health and best functional status but worst symptoms' [31].

Baseline data collected for both groups included participants' demographic information along with data on age, sex and diagnosis.

\section{Statistics}

Participants' characteristics are presented as means with standard deviation (SD) and as proportion. The two groups were compared at baseline using $X^{2}$ test for categorical variables and T-test or Wilcoxon rank sum test for continuous variables. Linear mixed effects models, using maximum likelihood estimation, were applied for each outcome variable, in order to estimate differences in changes of outcome from baseline to 1st and 2nd follow-up, respectively. The fixed part of the models included dummy variables for time of follow-up and treating hospital, and for interaction between time and hospital. Estimation of a fixed effect of treating hospital allowed for baseline differences in baseline measurements. The repeated measurements on patient level were modelled by including random intercepts of patients in the mixed model. Visual inspection of QQ-plots demonstrated deviations from normal distribution of the residuals; therefore bootstrapping methods using 10,000 repetitions were used when estimating the confidence intervals. Stata 16 (StataCorp. 2019. Stata Statistical Software: Release 16. College Station, TX: StataCorp LLC) was used for the statistical analysis.

The FAMCARE scores were calculated as both a total score and an individual item score. Consistent with previous approaches [32], we identified individuals scoring $\geq 64$ as generally satisfied, because this cut-off value is associated with rating satisfied on all 16 items. The results for individual FAMCARE items were dichotomized 
into satisfied (scores $\geq 4$ ) or dissatisfied (scores $\leq 3$ ), because those differences were deemed to be most clinically relevant.

\section{Results}

A total of 190 participants were enrolled in the study (67 from $\mathrm{R} / \mathrm{K}$ and 123 from N/S/N). During 2017, 1038 were registered to the SPC teams (371 to R/K and 667 to $\mathrm{N} /$ $\mathrm{S} / \mathrm{N})$. A total of 220 eligible patients were listed in the study while 113 were not. The SPC team nurse who was responsible for informing patients about the study and receiving potential participants' acceptance form was challenged for time. For this reason, including participants for research studies could not be prioritised. A total of 705 were invited to participate and, of those, 190 accepted the invitation. The flow of participants and their reasons for leaving the study is shown in Fig. 1. Of the 190 invited, 102 returned the first questionnaire and were thus included in the study; 55 returned the second questionnaire and 31 the third. Of the 102 the age range was 38 to 88, with a mean age of 68 (SD 9.47). Patients enrolled but not included were the 88 who did not return the first questionnaire. Of those, 80 died within 110 days and the mean residual life was 13 days. We found no difference between participants and those not included, with respect to sex, mean age or distribution between the hospitals.
At baseline, the only significant difference in demographic characteristics between the participants from $\mathrm{N} /$ $\mathrm{R}$ and N/S/N were their level of education, basis for income and distance to hospital, which was expected, given the hospitals' geographic location (Table 3).

At baseline, patients from hospitals $\mathrm{R} / \mathrm{K}$ had a significantly higher overall mean score for satisfaction with care ( 65.91 vs. $55.83 ; p=0.03$ ), measured by FAMCAREP16. Based on the individual score of $\geq 64$ as generally satisfied, patients from $\mathrm{R} / \mathrm{N}$ were satisfied, while patients from $\mathrm{N} / \mathrm{S} / \mathrm{N}$ were not satisfied, although in comparing each individual question, we found no significant differences between the two groups. However, more patients were satisfied with the availability of nurses as compared to that of doctors (Table 4).

Satisfaction with communication, measured by CPWQ-com, was equal in the two groups at baseline. More patients were satisfied with nurses' abilities to listen and communicate than doctors. In terms of QOL, measured by EORTC QLQ-C15-PAL, we found that patients from hospitals $\mathrm{R} / \mathrm{K}$ had a significantly higher mean score in relation to physical function (66.99 vs. 58.01; $p=0.01$ ). No other differences were found (Table 5).

Comparing differences in satisfaction from baseline to one and 3 months, we found no differences in development of either FAMCARE-P16 or CPWQ-com between the two hospitals.

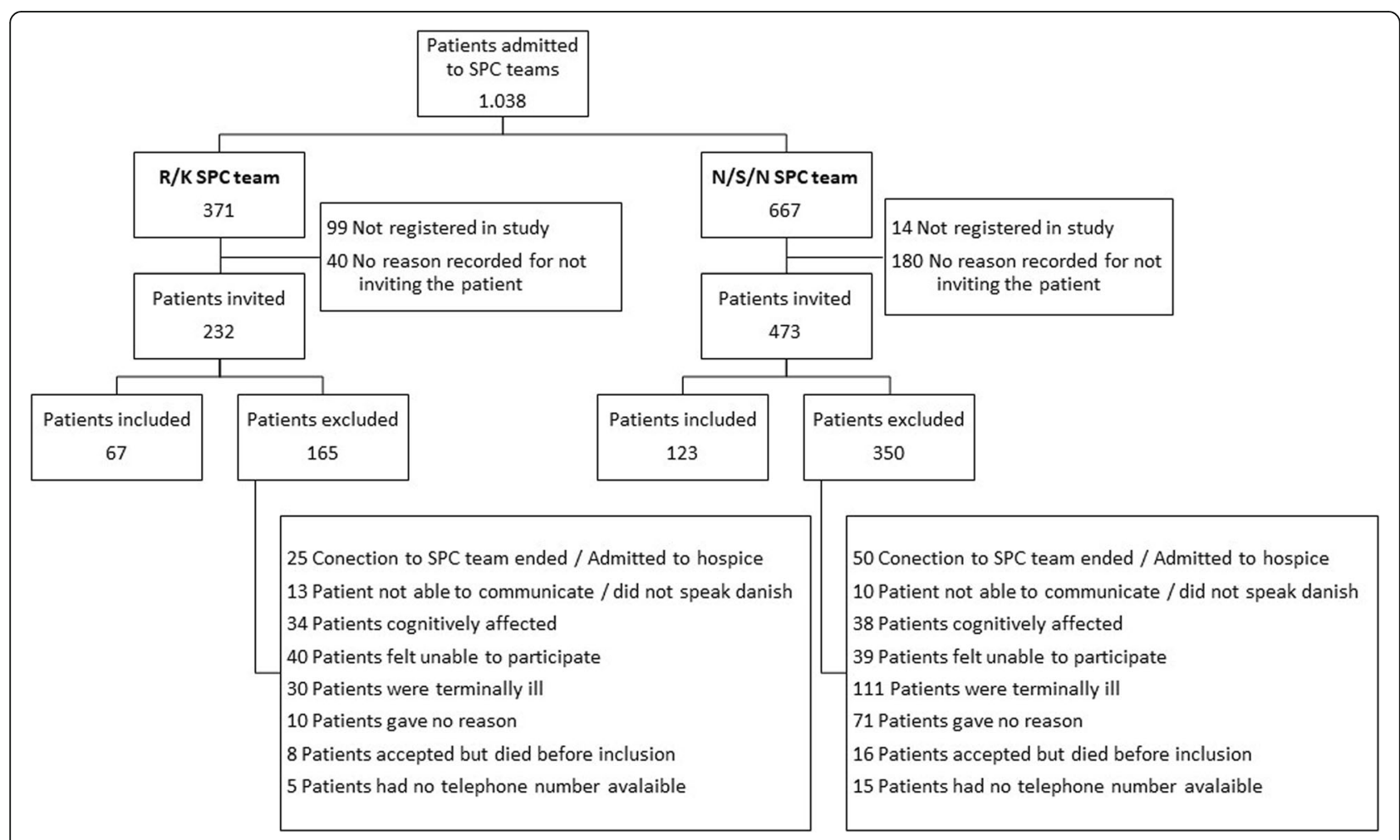

Fig. 1 Flow of participants and their reasons for leaving the study 
Table 3 Patient characteristics at baseline, $n=102$

\begin{tabular}{|c|c|c|c|c|c|}
\hline & \multicolumn{2}{|l|}{$\mathrm{R} / \mathrm{K}$} & \multicolumn{2}{|l|}{$\mathrm{N} / \mathrm{S} / \mathrm{N}$} & \multirow[t]{2}{*}{$p$ value } \\
\hline & Mean (SD) & n (\%) & Mean (SD) & n (\%) & \\
\hline Age & $70(9.1)$ & & $67(9.6)$ & & 0.13 \\
\hline Sex & & & & & 0.48 \\
\hline Female & & $19(55.9)$ & & $43(63.2)$ & \\
\hline Male & & $15(44.1)$ & & $25(36.8)$ & \\
\hline Marital status, $n=101$ & & & & & 0.69 \\
\hline Married/Cohabiting & & $25(73.5)$ & & $46(68.7)$ & \\
\hline Widowed & & $7(20.6)$ & & $13(19.4)$ & \\
\hline Divorced & & $2(5.9)$ & & $4(6.0)$ & \\
\hline Living alone & & $0(0)$ & & $4(6.0)$ & \\
\hline Children living at home, $n=101$ & & & & & 0.43 \\
\hline Yes & & $3(8.8)$ & & $3(4.5)$ & \\
\hline No & & $31(91.2)$ & & $64(95.5)$ & \\
\hline Education, $n=94$ & & & & & 0.02 \\
\hline Primary/Secondary schooling & & $6(18.2)$ & & $16(26.2)$ & \\
\hline Vocational training, less than 1 year & & $2(6.1)$ & & $1(1.6)$ & \\
\hline Vocational training, more than 1 year & & $2(6.0)$ & & $11(18.0)$ & \\
\hline Diploma & & $6(18.2)$ & & $17(27.9)$ & \\
\hline Bachelor & & $11(33.3)$ & & $14(23.0)$ & \\
\hline Master's degree or more & & $6(18.2)$ & & $2(3.3)$ & \\
\hline Income based on, $n=101$ & & & & & 0.01 \\
\hline Work & & $3(8.8)$ & & $11(16.4)$ & \\
\hline Sickness benefits & & $0(0)$ & & $2(3.0)$ & \\
\hline Early retirement & & $1(2.9)$ & & $6(9.0)$ & \\
\hline Pension & & $26(76.5)$ & & $48(71.6)$ & \\
\hline Self-employed & & $1(2.9)$ & & $0(0)$ & \\
\hline \multirow[t]{2}{*}{ Other } & & $3(8.8)$ & & $0(0)$ & \\
\hline & Mean (SD) & & Mean (SD) & & \\
\hline Distance to hospital, km & $11.0(7.0)$ & & $33.4(20.6)$ & & 0.00 \\
\hline Disease site, $n=98$ & & & & & 0.20 \\
\hline \multicolumn{6}{|l|}{ Cancer origin } \\
\hline Gastro-intestine & & $8(24.2)$ & & $19(29.2)$ & \\
\hline Lung & & $8(24.2)$ & & $21(32.3)$ & \\
\hline Breast/female genitals & & $5(15.2)$ & & $12(18.5)$ & \\
\hline Prostate & & $2(6.1)$ & & $1(1.5)$ & \\
\hline Other & & $8(24.2)$ & & $10(15.4)$ & \\
\hline Non-cancer & & $2(6.1)$ & & $2(3.1)$ & \\
\hline $\begin{array}{l}\text { Gamma-test for comparing ordinal data } \\
\text { Two sample t-test for comparing mean }\end{array}$ & & & & & \\
\hline
\end{tabular}

The development in overall QOL did not differ between the two hospitals at one or 3 months. However, in relation to the symptom insomnia, the mean difference in scores were significantly higher $p=0.01$ at 1 month follow-up for patients at hospital R/K (mean change -
28.81; SE 11.05). In addition, the development in the symptom constipation was significant $(p=0.04)$. The mean change was higher for patients from $\mathrm{R} / \mathrm{K}$ at 3 months follow-up (mean change -23.09; SE 11.25) (Table 6 and Fig. 2). 
Table 4 Comparison of satisfaction with care between groups at baseline

\begin{tabular}{|c|c|c|c|c|c|c|}
\hline & \multicolumn{2}{|l|}{$R / K$} & \multicolumn{2}{|l|}{$\mathrm{N} / \mathrm{S} / \mathrm{N}$} & \multirow[t]{2}{*}{$p$ value } & \multirow[t]{2}{*}{ Persons $\mathbf{R}$} \\
\hline & $n=24$ & & $n=42$ & & & \\
\hline FAMCARE-P16 score & Mean (SD) & & Mean (SD) & & & \\
\hline Total FAMCARE-P16 score, $n=66$ & $65.91(32.17)$ & & $55.83(29.60)$ & & 0.03 & \\
\hline Question: & & $\begin{array}{l}\text { Satisfied }{ }^{* *} \\
\text { n (\%) }\end{array}$ & & $\begin{array}{l}\text { Satisfied** } \\
\text { n (\%) }\end{array}$ & $p$ value $e^{* * *}$ & \\
\hline Information provided about prognosis & & $17(70.8)$ & & $30(71.4)$ & 0.96 & -0.006 \\
\hline Answers from health professionals & & $20(83.3)$ & & $36(85.7)$ & 0.80 & -0.032 \\
\hline Information given about side effects & & $17(70.8)$ & & $30(71.4)$ & 0.96 & -0.006 \\
\hline Referrals to specialists & & $16(66.7)$ & & $27(64.3)$ & 0.85 & 0.024 \\
\hline Speed with which symptoms are treated & & $19(79.2)$ & & $32(76.2)$ & 0.79 & 0.034 \\
\hline Doctor's attention to description of symptoms & & $18(75.0)$ & & $24(57.1)$ & 0.15 & 0.179 \\
\hline The way tests and treatments are performed & & $20(83.3)$ & & $35(83.3)$ & 1.00 & 0.000 \\
\hline Availability of doctors to answer questions & & $18(75.0)$ & & $26(61.9)$ & 0.26 & 0.134 \\
\hline Availability of nurses to answer questions & & $23(95.8)$ & & $39(92.9)$ & 0.63 & 0.060 \\
\hline Coordination of care & & $19(79.2)$ & & $32(76.2)$ & 0.79 & 0.034 \\
\hline Family inclusion in treatment/care decisions & & $18(75.0)$ & & $29(69.0)$ & 0.61 & 0.063 \\
\hline Information given about how to manage pain & & $20(83.3)$ & & $28(66.7)$ & 0.15 & 0.180 \\
\hline Information given about tests & & $18(75.0)$ & & $27(64.3)$ & 0.38 & 0.111 \\
\hline How thoroughly doctor assesses symptoms & & $18(75.0)$ & & $25(59.5)$ & 0.21 & 0.156 \\
\hline Follow-up on tests and treatments & & $19(79.2)$ & & $26(61.9)$ & 0.15 & 0.178 \\
\hline Availability of doctors to the family & & $18(75.0)$ & & $22(52.4)$ & 0.07 & 0.223 \\
\hline \multirow[t]{2}{*}{ CPWQ-com score } & $n=25$ & & $n=48$ & & & \\
\hline & Mean (SD) & & Mean (SD) & & & \\
\hline CPWQ-com, $n=73$ & $76.43(33.11)$ & & $73.75(19.10)$ & & 0.52 & \\
\hline Question: & & $\begin{array}{l}\text { Satisfied** } \\
\text { n (\%) }\end{array}$ & & $\begin{array}{l}\text { Satisfied** } \\
\text { n (\%) }\end{array}$ & $p$ value $e^{* * *}$ & \\
\hline Have the doctors been good at communicating? & & $21(84.0)$ & & $38(79.2)$ & 0.62 & 0.058 \\
\hline Have the doctors used understandable language? & & $22(88.0)$ & & $40(83.3)$ & 0.60 & 0.062 \\
\hline Have the doctors been good at listening to you? & & $22(88.0)$ & & $40(83.3)$ & 0.60 & 0.062 \\
\hline Have the nurses been good at communicating? & & $24(96.0)$ & & $47(97.9)$ & 0.64 & -0.056 \\
\hline Have the nurses been good at listening to you? & & $24(96.0)$ & & $46(95.8)$ & 0.97 & 0.004 \\
\hline Has information been provided at the appropriate time? & & $20(87.0)$ & & $42(87.5)$ & 0.95 & -0.008 \\
\hline Have the staff allowed enough time for consultations? & & $21(87.5)$ & & $44(91.7)$ & 0.58 & -0.066 \\
\hline $\begin{array}{l}\text { *Independent t-test for comparing mean - equal variance } \\
\text { ** scoring } 1 \text { "very satisfied" or } 2 \text { "satisfied" } \\
\text { *** Persons R }\end{array}$ & & & & & & \\
\hline
\end{tabular}

\section{Discussion}

In this study, we found no differences over time between the two models of SPC consultations in terms of overall satisfaction, satisfaction with communication or overall QOL. We found a significant difference in the development of the symptom insomnia at 1 month and in constipation at 3 months. At baseline, there were no significant differences in the symptom insomnia between the two groups that scored in mean $26(\mathrm{R} / \mathrm{K})$ and $34(\mathrm{~N} /$ $\mathrm{S} / \mathrm{N})$. But, at the 1 month follow-up, patients from both groups reported much higher mean scores, i.e. $85(\mathrm{R} / \mathrm{K})$ and $64(\mathrm{~N} / \mathrm{S} / \mathrm{N})$, reflecting a worsening of their insomnia, which was more severe at hospital $\mathrm{R} / \mathrm{K}$. In comparison, Nordic studies found a mean score of 24 in a nationally representative sample of advanced cancer patients in Denmark [2] and 39-41in a regional sample of cancer patients in Norway admitted to palliative care [33]. SPC involves the sub-group of patients who are most burdened by symptoms and problems; and as SPC is initiated at the end-stage of life, progression of the 
Table 5 Comparison of symptom control, physical and emotional function and quality of life at baseline

\begin{tabular}{llll}
\hline EORTC QLQ-C15-PAL & $\begin{array}{l}\text { R/K } \\
\boldsymbol{n}=\mathbf{3 4} \\
\text { Mean (SD) }\end{array}$ & $\begin{array}{l}\text { N/S/N } \\
\boldsymbol{n}=\mathbf{6 8} \\
\text { Mean (SD) }\end{array}$ & p value \\
\hline $\begin{array}{llll}\text { Functional scale: } \\
\text { Physical functioning }\end{array}$ & $66.99(20.38)$ & $58.01(29.48)$ & 0.01 \\
$\quad$ Emotional functioning & $69.61(22.27)$ & $73.00(26.25)$ & 0.36 \\
Symptom scale: & & & \\
Fatigue & $54.90(25.14)$ & $56.62(24.63)$ & 0.74 \\
Nausea and vomiting & $20.59(24.64)$ & $27.36(34.29)$ & 0.23 \\
Pain & $45.10(31.92)$ & $49.26(32.89)$ & 0.53 \\
Dyspnoea & $28.43(33.97)$ & $33.82(32.83)$ & 0.46 \\
Insomnia & $26.47(28.16)$ & $33.82(31.80)$ & 0.21 \\
Appetite loss & $45.10(30.58)$ & $39.30(32.27)$ & 0.38 \\
Constipation & $15.69(27.51)$ & $23.38(29.60)$ & 0.18 \\
Global Health: & & & \\
QLQ & $43.43(22.41)$ & $50.51(23.56)$ & 0.10 \\
\hline
\end{tabular}

disease and symptoms is often rapid [2]. Patients may thus experience a worsening of symptoms, which may explain the higher mean score for such palliative care patients. Johnsen et al. found insomnia to be one of the most frequent symptoms in advanced cancer patients [2], and Rabow et al. found that sleep quality improved with outpatient palliative medicine consultations [13].
However, this was not the case in our study. On the contrary, it seems that patients sleep quality worsened and more so at the hospital R/K. An important difference between the included hospitals were the location and duration of the initial visit. The SPC team from N/ S/N did home visits that often lasted more than 1 hour, which may well have helped patients to establish a closer, more trusting relationship with the team during the first consultation. This resulted in a more comprehensive symptom assessment. Getting a chance to know the team and establish a relationship along with being involved are some of the fundamental perspectives of open and effective communication, and represent two of the core themes in a person-centred approach to care [34]. Context is the third theme found by Kitson et al. (2013) [34]. Even though Wentlandt et al. (2016) found that home visits represent a non-institutionalized setting that allows for both privacy and socialization [10], sufficient time resource allocation and a qualified SPC team who have chosen to work within the palliative care setting and who are dedicated to offering a person-centred approach seem to be at least as important as the setting in which the consultation takes place.

In relation to communication, between 95.8 and $97.9 \%$ of the patients found, the nurses to be good at both listening and communicating, and more patients were satisfied with nurses' abilities to listen and communicate than they were with doctors' abilities; which was also found by Ross [35]. In our study, the nurses conducted

Table 6 Change between groups in satisfaction, physical and emotional function, symptom control, and quality of life

\begin{tabular}{|c|c|c|c|c|}
\hline & \multicolumn{2}{|c|}{ Differences in change from baseline to $1 \mathrm{st}$ follow-up } & \multicolumn{2}{|c|}{ Differences in change from baseline to 2 nd follow-up } \\
\hline & Mean (SE) & $P$ & Mean (SE) & $p$ \\
\hline FAMCARE-P16 & $0.78(7.33)^{b}$ & 0.92 & $-1.66(9.07)^{\mathrm{a}}$ & 0.86 \\
\hline CPWQ-com & $-1.30(7.01)^{\mathrm{a}}$ & 0.85 & $2.63(7.45)^{\mathrm{b}}$ & 0.74 \\
\hline \multicolumn{5}{|l|}{ EORTC QLQ-C15-PAL } \\
\hline \multicolumn{5}{|l|}{ Functional scale: } \\
\hline Physical functioning & $3.08(5.86)^{b}$ & 0.60 & $4.15(6.77)^{\mathrm{b}}$ & 0.54 \\
\hline Emotional functioning & $-0.82(7.15)^{\mathrm{a}}$ & 0.91 & $8.89(10.65)^{b}$ & 0.40 \\
\hline \multicolumn{5}{|l|}{ Symptom scale: } \\
\hline Fatigue & $-7.42(8.92)^{\mathrm{a}}$ & 0.41 & $2.89(11.72)^{b}$ & 0.81 \\
\hline Nausea and vomiting & $-4.71(10.73)^{\mathrm{a}}$ & 0.66 & $-2.33(11.47)^{\mathrm{a}}$ & 0.84 \\
\hline Pain & $-6.44(12.10)^{a}$ & 0.60 & $-11.87(12.76)^{a}$ & 0.35 \\
\hline Dyspnoea & $-9.47(13.04)^{\mathrm{a}}$ & 0.47 & $2.02(17.22)^{b}$ & 0.91 \\
\hline Insomnia & $-28.81(11.045)^{a}$ & 0.01 & $-17.19(14.42)^{a}$ & 0.23 \\
\hline Appetite loss & $6.85(13.18)^{b}$ & 0.60 & $19.13(15.49)^{b}$ & 0.22 \\
\hline Constipation & $-6.53(10.32)^{a}$ & 0.53 & $-23.09(11.25)^{a}$ & 0.04 \\
\hline \multicolumn{5}{|l|}{ Global Health: } \\
\hline QLQ & $-3.79(7.34)^{a}$ & 0.61 & $3.88(9.97)^{b}$ & 0.70 \\
\hline
\end{tabular}

${ }^{a} \mathrm{~A}$ negative number indicates that R/K's patients' symptoms are increasing or $\mathrm{QOL}$ score are decreasing more relative to $\mathrm{N} / \mathrm{S} / \mathrm{N}$ 's patients

${ }^{\mathrm{b}} \mathrm{A}$ positive number indicates that $\mathrm{R} / \mathrm{K}^{\prime} \mathrm{s}$ patients' symptoms are decreasing or $\mathrm{QOL}$ score are increasing more relative to $\mathrm{N} / \mathrm{S} / \mathrm{N}$ 's patients 

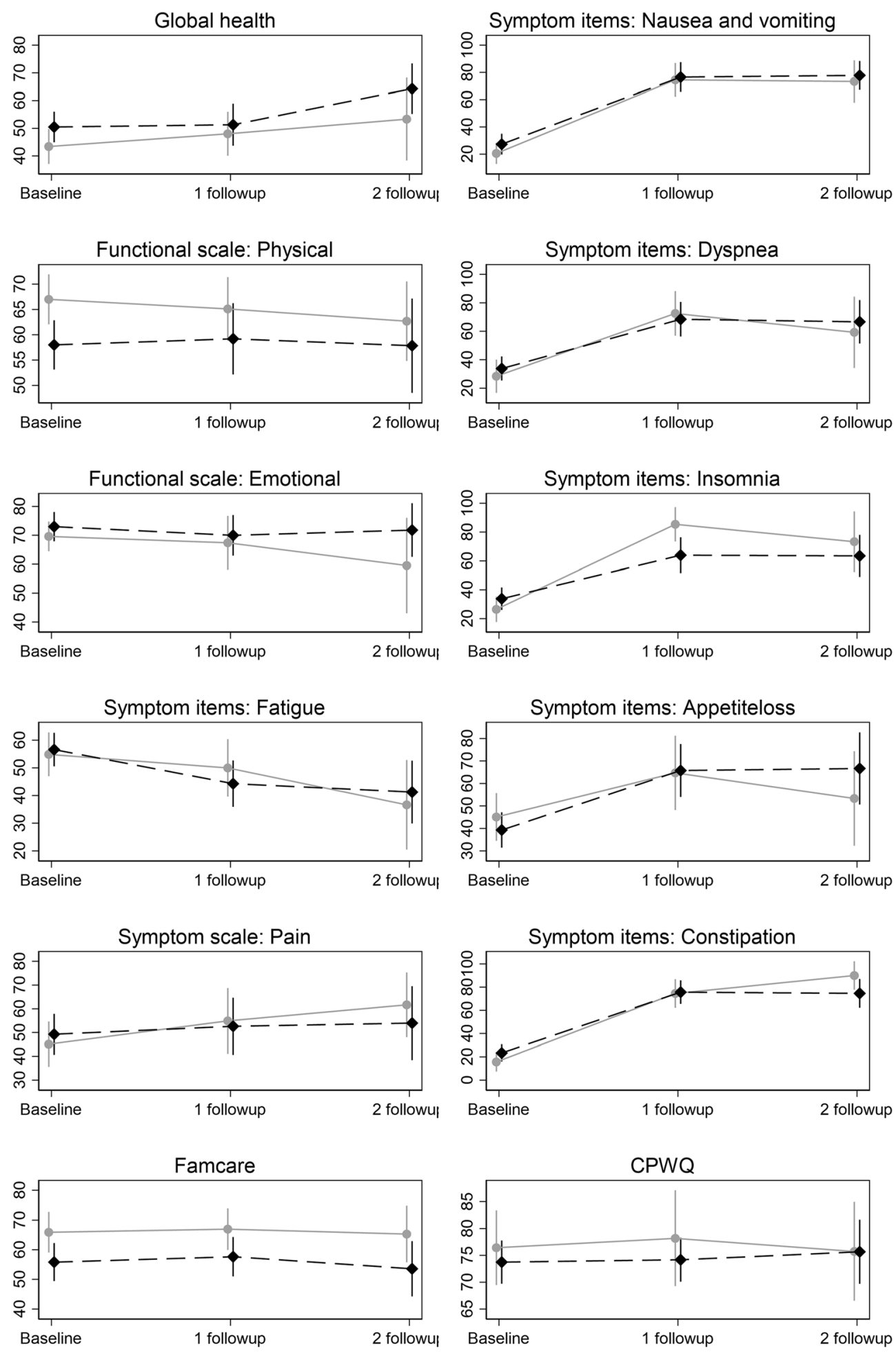

\section{$\mathrm{R} / \mathrm{K}$ \\ $\mathrm{N} / \mathrm{S} / \mathrm{N}$}

Fig. 2 Development in QOL, symptoms, satisfaction and communication 
the follow-up telephone consultations and were first in line to answer phone calls from the patients. This division of labour may also reflect the reason why nurses were perceived as available and therefore able to answer questions to a larger degree than were doctors. The very high number of patients who were satisfied with the nurses' communication indicates that the nurses succeeded in not only open communication, but also in possessing the personal qualities such as being polite, respectful, sensitive and welcoming [34]. All those abilities should be present in establishing a therapeutic nurse/patient relationship. This appears to be crucial to ensuring and identifying patients' holistic needs, and to their involvement in decision-making. A holistic approach is a factor that is important to patients, when health professionals provide emotional support and support patients' lives [36].

We know from previous studies that SPC improves satisfaction with care [13, 37, 38]. In this study, we found a significant difference in satisfaction at baseline between the two groups - patients from R/K scored significantly higher, with a mean score of 65.91 , as opposed to N/S/ N55.83 at, $p=0.03$. In examining the individual items, the ones representing the biggest difference are those concerning attention and information from doctors. This probably reflects the fact that the patients at N/S/N only see a doctor during their first consultation, and even though it is a home visit, follow-up is primarily conducted by the patients' GPs and community home care nurses. In comparison, patients from $\mathrm{R} / \mathrm{K}$ have follow-up consultations that are conducted by a doctor and nurse from the SPC team every 3 weeks and, in the meantime, if needed, follow-up phone calls with SPC nurses. In addition, the SPC team at $\mathrm{N} / \mathrm{S} / \mathrm{N}$ only had one doctor to cover all home visits, which meant there was very little time to respond to patients' unscheduled enquiries. The difference in satisfaction concerning attention and information from doctors might have been more related to pressure of work rather than to personal ability. The level of staffing is critical and, as shown in Table 2, R/N had a broader multidisciplinary team than did $\mathrm{N} / \mathrm{S} / \mathrm{N}$. To access non-medical, non-nursing members of the team, the patients needed a referral from the team doctor or nurse, which may also have meant a restriction on access to the multidisciplinary team members. The shortage of doctors was also reflected in the longer waiting time at $\mathrm{N} / \mathrm{S} / \mathrm{N}$, compared to $\mathrm{R} / \mathrm{K}$ [5]. This represents inequality in access to SPC and may be another explanation as to why patients were less satisfied at N/S/N. For those patients, the inequality is exacerbated by living in a rural area, which is characterised by a shortage of GPs as well as a lower level of income and education [39]. Other studies have shown that rural residents may be less likely to receive palliative care [40, 41]. Besides, those who do not receive palliative care are more likely to receive potentially aggressive end-of-life care, spend more days in hospital in the last part of life and die in an acute care hospital $[41,42]$. One reason why the difference in satisfaction is not great may be that the SPC team is made up of professionals who have actively chosen palliation as their profession and that they are dedicated to and focused on providing a person-centred approach.

A strength of the study was that patients were included from a broad, heterogeneous area and the inclusion period proceeded for 1 year. In addition, data were collected not only at baseline but also one and 3 months later. This gave us a picture of the development over time and allowed us to reveal consequences of inequity in the SPC.

On the other hand, even though we included participants over a year, only 102 of the 705 possible participants returned the first questionnaire. This may have introduced a selection bias, as the mean residual life of included patients was longer than for those who did not return the first questionnaire. Further, both symptoms and QOL seemed to worsen in the late palliative care phase, which we may not have captured. We used questionnaires to collect data; a limitation to this approach may be that, despite being validated, answers are limited to the questions asked. We would have liked to elicit more detailed and nuanced patient perspectives on what it was in the SPC consultations that was important to them. We therefore conducted interviews in a later study.

\section{Conclusion}

Specialist palliative care is in request for many patients during the late phase of their disease. Outpatient SPC may be organized using a wide variety of models. In this article, we describe two such models - one of which involves the first encounter in the form of a home visit, while, in the other, the first encounter takes place in a hospital-based outpatient clinic. We analysed the two models using a questionnaire design and found no significant difference in satisfaction with care, communication with health professionals or in overall quality of life. In fact, it seems more important that patients have access to SPC than which model is used. Furthermore, patient participation and involvement in care seem to be important to level of satisfaction, and it may that the time available matters more than the context. Thus, SPC must leave room for a person-centred and individual approach concerning symptom control, psychosocial and spiritual support, as well as for practical issues.

\section{Abbreviations}

CPWQ-com: Cancer Patient's World Questionnaire - communication; EORTC

QLQ-C15-PAL: European Organization for Research and Treatment of Cancer 
Quality of Life Questionnaire Core 15 - Palliative Care; FAMCARE: Family satisfaction; GP: General practitioner; N/S/N: Naestved/Slagelse/Nykoebing F; QOL: Quality of life; R/K: Roskilde/Koege; SD: Standard deviation; SE: Standard error; SPC: Specialist palliative care

\section{Acknowledgements}

The authors would like to thank all the staff working in the palliative care departments at Zealand University Hospital for their valuable participation in the inclusion of participants. For her help with statistics, thanks goes to Inge Petersen, OPEN, Odense University Hospital and Department of Clinical Research, University of Southern Denmark. Lorna Campbell is acknowledged for linguistic revision.

\section{Authors' contributions}

All authors (ER, BMÅ, BHH, MR) contributed to the design of the work or data collection, analysis, and interpretation of data; participated in revision; gave final approval of the version to be published; and agreed to be responsible for the work. The authors read and approved the final manuscript.

\section{Funding}

The study was supported by the Novo Nordisk Foundation. The funding body did not participate in any part of the study (neither in the design, collection of data, analysis, interpretation, nor in the writing of the manuscript). Open Access funding provided by Novo Nordisk Foundation.

\section{Availability of data and materials}

The datasets used and/or analysed during the current study are available from the corresponding author upon reasonable request.

\section{Ethics approval and consent to participate}

The Regional Ethical Committee of the Zealand Region confirmed that approval for the study was not required according to Danish law, given the non-biomedical character of the study (j. nr. 16-000014). The Regional Ethical Committee is organised under the Danish Council on Ethics, which is a parliamentary and governmental council. The study was registered with the Danish Data Protection Agency, (j.nr. REG-112-2016).

All participants were given both written and verbal information about the study. All adult patients registered to one of the two outpatient SPC sections during 2017 received written information about the study at their first consultation. Those who consented received a telephone call from the first author within the next week informing them about the study and asking them to participate in the questionnaire. Those who consented were included and returned a written consent form. It was emphasized that participants' anonymity would be maintained in the reporting of the results. A fundamental ethical principle in research is beneficence, meaning that the research must not do any harm because of the way in which it is conducted. Patients who receive SPC are often seriously ill and vulnerable, which is why there may be objections to their inclusion in research. However, studies show that participation makes sense to palliative care patients, and that they wish to contribute with their experiences [43]. An SPC nurse conducted the interviews, and during the interviews, she showed empathy and respect and took time to listen to the participants' stories.

\section{Consent for publication}

Not applicable.

\section{Competing interests}

The authors declare that they have no competing interests.

\section{Author details}

'Department of Oncology and Palliative Care, Zealand University Hospital, Sygehusvej 10, 4000 Roskilde, Denmark. ${ }^{2}$ Department of Regional Health Research, University of Southern Denmark, J. B. Winsløws Vej 19, 5000 Odense C, Denmark. ${ }^{3}$ Department of Research Support, Zealand University Hospital, Munkesøvej 14, 4000 Roskilde, Denmark. ${ }^{4}$ REHPA, The Danish Knowledge Centre for Rehabilitation and Palliative Care, Odense University Hospital and University of Southern Denmark, Nyborg, Denmark.
Received: 27 November 2020 Accepted: 10 February 2021 Published online: 18 February 2021

\section{References}

1. Nielsen KT, Raunkiær M. Palliative care to the elderly with chronic heart failure - a systematic litterature review (in Danish). Nordic J Nurs Res. 2014; 34(2):38-43

2. Johnsen AT, Petersen MA, Pedersen L, Groenvold M. Symptoms and problems in a nationally representative sample of advanced cancer patients. Palliat Med. 2009;23(6):491-501.

3. Lannie A, Peelo-Kilroe L. Person-centredness in palliative care. In: T MBM editor. Person-Centred practice in nursing and health care: theory and practice. West Sussex: Wiley; 2017. p. 248-58.

4. Stiefel F, Trill M, Berney A, Olarte J, Razavi D. Depression in palliative care: a pragmatic report from the expert working Group of the European Association for palliative care. Support Care Cancer. 2001;9(7):477-88.

5. Hansen MB, Adsersen M, Grønvold M. Danish Palliativ care database: annual report 2019 Copenhagen: DMCG-PAL; 2020 [cited 2020]. Available from: http://www.dmcgpal.dk/files/dpd/aarsrapport/aarsrapport_dpd_2019.pdf

6. Danish Health Authority. Anbefalinger for den palliative indsats [Recomendations for the palliative care effort]. Danish Health Authority; 2017. https://www.sst.dk/-/media/Udgivelser/2017/Anbefalingerfor-den-palliative-indsats.ashx?la=da\&hash=F79F0E7E531E15E1B4A3FC9642 CCA37B15D798C9

7. Gaertner J, Siemens W, Meerpohl JJ, Antes G, Meffert C, Xander C, et al. Effect of specialist palliative care services on quality of life in adults with advanced incurable illness in hospital, hospice, or community settings: systematic review and meta-analysis. Bmj. 2017;357:j2925.

8. Kavalieratos D, Corbelli J, Zhang D, Dionne-Odom JN, Ernecoff NC, Hanmer J, et al. Association between palliative care and patient and caregiver outcomes: a systematic review and meta-analysis. JAMA. 2016;316(20):2104-14.

9. Seccareccia D, Wentlandt K, Kevork N, Workentin K, Blacker S, Gagliese L, et al. Communication and quality of care on palliative care units: a qualitative study. J Palliat Med. 2015;18(9):758-64.

10. Wentlandt K, Seccareccia D, Kevork N, Workentin K, Blacker S, Grossman D, et al. Quality of care and satisfaction with care on palliative care units. J Pain Symptom Manag. 2016;51(2):184-92.

11. Hui D, Hannon BL, Zimmermann C, Bruera E. Improving patient and caregiver outcomes in oncology: team-based, timely, and targeted palliative care. CA Cancer J Clin. 2018;68(5):356-76.

12. Dy SM, Shugarman LR, Lorenz KA, Mularski RA, Lynn J, Center R-SCE-BP. A systematic review of satisfaction with care at the end of life. J Am Geriatr Soc. 2008;56:124-9.

13. Rabow M, Kvale E, Barbour L, Cassel JB, Cohen S, Jackson V, et al. Moving upstream: a review of the evidence of the impact of outpatient palliative care. J Palliat Med. 2013;16(12):1540-9.

14. Follwell M, Burman D, Le LW, Wakimoto K, Seccareccia D, Bryson J, et al. Phase II study of an outpatient palliative care intervention in patients with metastatic Cancer. J Clin Oncol. 2009;27(2):206-13.

15. Zimmermann C, Riechelmann R, Krzyzanowska M, Rodin G, Tannock I. Effectiveness of specialized palliative care: a systematic review. JAMA. 2008; 299:1698-709.

16. Hui D. Palliative Cancer Care in the Outpatient Setting: which model works best? Curr Treat Options in Oncol. 2019;20(2):17.

17. Korngut S, Johnsen A, Neergaard M, Grønvold M. The cancer patients experience of the palliative fase of the disease (in Danish). The Danish Cancer Society: Copenhagen; 2012

18. Groenvold M, Petersen MA, Damkier A, Neergaard MA, Nielsen JB, Pedersen $L$, et al. Randomised clinical trial of early specialist palliative care plus standard care versus standard care alone in patients with advanced cancer: the Danish palliative care trial. Palliat Med. 2017;31(9):814-24.

19. Nordly M, Skov Benthien K, Vadstrup ES, Kurita GP, von Heymann-Horan AB, von der Maase $\mathrm{H}$, et al. Systematic fast-track transition from oncological treatment to dyadic specialized palliative home care: DOMUS - a randomized clinical trial. Palliat Med. 2019;33(2):135-49.

20. Steinhauser KE, Christakis NA, Clipp EC, McNeilly M, McIntyre L, Tulsky JA. Factors considered important at the end of life by patients, family, physicians, and other care providers. Jama. 2000;284(19):2476-82.

21. Teno JM, Clarridge BR, Casey V, Welch LC, Wetle T, Shield R, et al. Family perspectives on end-of-life care at the last place of care. Jama. 2004:291(1): 88-93. 
22. Knaul FM, Bhadelia A, Rodriguez NM, Arreola-Ornelas H, Zimmermann C The lancet commission on palliative care and pain relief-findings, recommendations, and future directions. Lancet Glob Health. 2018;6:S5-6.

23. Creswell JW. A concise introduction to mixed methods research. USA: SAGE Publications, INC.; 2015.

24. Hansen MB, Adsersen A, Grønvold M. Danish Palliativ care database: annual report 2017. DMCG-PAL: Copenhagen; 2018.

25. World Health Organization. WHO definition of palliative care [cited 2019 July 1]. Available from: http://www.who.int/cancer/palliative/definition/en/.

26. Johnsen AT, Damkier A, Vejlgaard TB, Lindschou J, Sjøgren P, Gluud C, et al. A randomised, multicentre clinical trial of specialised palliative care plus standard treatment versus standard treatment alone for cancer patients with palliative care needs: the Danish palliative care trial (DanPaCT) protocol. BMC Palliative Care. 2013;12:37.

27. Lo C, Burman D, Rodin G, Zimmermann C. Measuring patient satisfaction in oncology palliative care: psychometric properties of the FAMCARE-patient scale. Qual Life Res. 2009;18(6):747-52.

28. Ross L, Lundstrom LH, Petersen MA, Johnsen AT, Watt T, Groenvold M. Using method triangulation to validate a new instrument (CPWQ-com) assessing cancer patients' satisfaction with communication. Cancer Epidemiol. 2012;36(1):29-35.

29. Groenvold M, Petersen MA, Aaronson NK, Arraras Jl, Blazeby JM, Bottomley A, et al. The development of the EORTC QLQ-C15-PAL: a shortened questionnaire for cancer patients in palliative care. Eur J Cancer. 2006;42(1):55-64.

30. Aaronson NK, Ahmedzai S, Bergman B, Bullinger M, Cull A, Duez NJ, et al. The European Organization for Research and Treatment of Cancer QLQ-C30: a quality-of-life instrument for use in international clinical trials in oncology. J Natl Cancer Inst. 1993:85(5):365-76.

31. Groenvold T, Petersen MA. On behalf of the EORTS quality of life group. Addendum to the EORTC QLQ-C30 scoring manual: scoring of the EORTC QLQ-C15-PAL. European organisation for Research and Treatment of Cancer: Brussels, Belgium; 2006.

32. Ringdal Gl, Jordhoy MS, Kaasa S. Measuring quality of palliative care: psychometric properties of the FAMCARE scale. Qual Life Res. 2003;12(2):167-76.

33. Jordhoy MS, Fayers P, Loge JH, Ahlner-Elmqvist M, Kaasa S. Quality of life in palliative cancer care: results from a cluster randomized trial. J Clin Oncol. 2001;19(18):3884-94.

34. Kitson A, Marshall A, Bassett K, Zeitz K. What are the core elements of patient-centred care? A narrative review and synthesis of the literature from health policy, medicine and nursing. J Adv Nurs. 2013;69(1):4-15.

35. Ross L, Petersen MA, Johnsen AT, Lundstrom LH, Groenvold M. Cancer patients' evaluation of communication: a report from the population-based study 'The Cancer Patient's World'. Support Care Cancer. 2013;21(1):235-44.

36. Stahlke S, Rawson K, Pituskin E. Patient perspectives on nurse practitioner Care in Oncology in Canada. J Nurs Scholarship. 2017;49(5):487-94.

37. Davis MP, Temel JS, Balboni T, Glare P. A review of the trials which examine early integration of outpatient and home palliative care for patients with serious illnesses. Annals Palliative Med. 2015:4(3):99-121.

38. Zimmermann C, Swami N, Krzyzanowska M, Hannon B, Leighl N, Oza A, et al. Early palliative care for patients with advanced cancer: a clusterrandomised controlled trial. Lancet. 2014;383(9930):1721-30.

39. Medical coverage throughout Denmark (in Danish). Copenhagen: Danish Health Authority; 2017.

40. Tedder T, Elliott $L$, Lewis $K$. Analysis of common barriers to rural patients utilizing hospice and palliative care services: an integrated literature review. J Am Assoc Nurse Pract. 2017;29(6):356-62.

41. Conlon MS, Caswell JM, Santi SA, Ballantyne B, Meigs ML, Knight A, et al. Access to palliative Care for Cancer Patients Living in a northern and rural environment in Ontario, Canada: The Effects of Geographic Region and Rurality on End-of-Life Care in a Population-Based Decedent Cancer Cohort. Clin Med Insights Oncol. 2019:13:1179554919829500.

42. Walter J, Tufman A, Leidl R, Holle R, Schwarzkopf L. Rural versus urban differences in end-of-life care for lung cancer patients in Germany. Support Care Cancer. 2018;26(7):2275-83,

43. Gysels M, Shipman C, Higginson IJ. "I will do it if it will help others:" motivations among patients taking part in qualitative studies in palliative care. J Pain Symptom Manag. 2008;35(4):347-55

\section{Publisher's Note}

Springer Nature remains neutral with regard to jurisdictional claims in published maps and institutional affiliations.

\section{Ready to submit your research? Choose BMC and benefit from:}

- fast, convenient online submission

- thorough peer review by experienced researchers in your field

- rapid publication on acceptance

- support for research data, including large and complex data types

- gold Open Access which fosters wider collaboration and increased citations

- maximum visibility for your research: over $100 \mathrm{M}$ website views per year

At BMC, research is always in progress.

Learn more biomedcentral.com/submissions 